\title{
El uso del álbum ilustrado como herramienta para el desarrollo de la competencia literaria y la mejora de la inclusión en Educación Infantil
}

\author{
* Ylenia Larriet Suárez
}

\author{
PALABRAS CLAVE \\ Educación inclusiva \\ Álbum ilustrado \\ Literatura infantil y juvenil \\ Conversación literaria \\ Educación infantil \\ Respuestas lectoras
}

\section{KEYWORDS}

Inclusive education

Picturebook

Children's literature

Literary discussion

Early childhood education

Literary responses

\begin{abstract}
RESUMEN
A través de una educación inclusiva se pretende atender a la diversidad de la sociedad actual, ofreciendo una educación para todo el alumnado. Una herramienta eficaz para ello puede ser la conversación literaria, compartiendo opiniones o ideas sobre las lecturas, pues permite trabajar de forma transversal. Partiendo de lo expuesto, este trabajo pretende comprobar la contribución de la lectura compartida de álbumes ilustrados, combinada con la conversación literaria, a la mejora de la inclusión y la competencia literaria en un aula de Educación Infantil. Para ello, se adopta una metodología de corte exploratorio, basada un estudio de caso a través del diseño, aplicación y análisis de las respuestas lectoras suscitadas por la lectura compartida, empleando el enfoque DIME, en una muestra de 34 escolares entre los tres y cinco años de un centro educativo del Principado de Asturias. Se emplea la observación participante, diario de campo, entrevistas con las maestras y grabaciones de audio para la obtención de datos y Atlas Ti como software específico para el análisis de datos. Los resultados reflejan que la conversación literaria permite la creación de un clima acogedor en el que todo el alumnado participa, se relaciona e intercambia opiniones basadas en el respeto y la tolerancia.
\end{abstract}

The use of picturebook as a tool to improve inclusion in early childhood education

\begin{abstract}
Inclusive education tries to attend all the diversity of our society, offering education to every student and enhancing the full development of everyone among their peers. One effective tool for that could be literary discussion, talking about books, sharing opinions and ideas, as it allows to work taking a multi-disciplinary approach. To test this, the investigation tries to improve literary competence and inclusion based on picturebook reading and literary discussion. So it is an exploratory study, based on a case study by the design, application and analysis of the literary responses of a literary discussion through "Tell me" method with a sample of 34 pupils, aged three to five years old, in a school of the Principality of Asturias. Participant observation, field diary, interviews with teachers and audio recording have been used to collect data. Atlas Ti software has been used to analyse data. The results reflect that literary discussion allows the creation of a comfortable atmosphere in which every student contributes, interacts and exchanges opinions based on respect and tolerance.
\end{abstract}

Universidad de Oviedo

Autora de correspondencia: * Ylenia Larriet Suárez; ylenialarriet@gmail.com

Recibido: 27/07/2020 - Aceptado: 30/03/2021

Revista de Formación del Profesorado e Investigación Educativa

Facultad de Formación del Profesorado y Educación

Universidad de Oviedo

Julio - Diciembre 2020

ISSN: 2340-4728

(c) (1) () $\Theta$ Esta obra está bajo una licencia internacional Creative Commons

Atribución-NoComercial-SinDerivadas 4.0. 


\section{Introducción}

\section{Educación inclusiva}

La diversidad es una de las características de la sociedad actual y la escuela debe reconocerla y respetarla. Alba et al. (2014, p.1) hablan de "diversidad de diversidades", entendiendo que cada aula cuenta con un alumnado único, ya que cada alumno y alumna proviene de una familia distinta, con características diferentes, intereses diversos y una personalidad única. Arnaiz (2000) reconoce que la educación debe comprometerse a utilizar metodologías diferentes para dar respuesta a la diversidad, teniendo en cuenta las diferencias individuales y valorando a la persona por encima de ellas. A su vez, Chaves et al. (2018) sostienen que es necesario replantear la escuela a partir de un nuevo modelo de educación, teniendo en cuenta toda la diversidad del alumnado.

Hoy en día se habla de educación inclusiva, un término y una práctica poliédrica (Ainscow y Booth, 2006; Echeita, 2008), considerada como una aspiración a lograr, en la que todas las personas sean valoradas por igual. Muchos y muchas docentes lo consideran un reto, pues no se cuenta con todos los apoyos ni las ayudas necesarias para atender a cada individuo de manera personalizada (Jiménez et al., 2018; González-Gil et al., 2017). La educación inclusiva va más allá del sentimiento de valoración y pertenencia, ya que se quiere lograr un aprendizaje de calidad para todas las personas, acorde a las necesidades y capacidades de cada persona (Echeita, 2006). Para ello, Alba et al. (2014) elabora el Diseño Universal de Aprendizaje, donde se reúnen los principios fundamentales para desarrollar un currículum accesible a todo el alumnado. Asimismo, la Organización de las Naciones Unidas para la Educación, la Ciencia y la Cultura (UNESCO, 2004) sostiene que la inclusión ha de ser un principio orientador de todas las políticas de centro y programas educativos.

En muchas ocasiones, se entiende que la educación inclusiva va ligada al alumnado con necesidades educativas especiales pero no tiene por qué, ya que existen muchas otras desigualdades y exclusiones a nivel de diferencias personales de cada uno, ya sean por alguna discapacidad, género, cultura o edad (Blanco, 2010). Se debe tener en cuenta que todo el alumnado puede sentirse excluido en algún momento.

Desde hace varios años se promueve a través de las leyes educativas una educación inclusiva. La Ley Orgánica 8/2013, de 9 de diciembre, para la mejora de la calidad educativa no ha generado cambios con respecto a la Educación Infantil. Por ende, el profesorado ha de guiarse por el texto consolidado entre la Ley Orgánica 8/2013 de 9 de diciembre para la mejora de la calidad educativa y la anterior Ley Orgánica 2/2006 de 3 de mayo, de educación. En ella se recoge que "el reconocimiento de esta diversidad entre alumno o alumna en sus habilidades y expectativas es el primer paso hacia el desarrollo de una estructura educativa que contemple diferentes trayectorias" (p. 3).

En lo referente al nivel autonómico, en Asturias, el Decreto 85/2008, de 3 de septiembre, por el que se establece el currículo del segundo ciclo de Educación Infantil, dedica el Capítulo V a la "Atención a la diversidad". Esta es entendida como una serie de actuaciones educativas para responder a las capacidades, ritmos, estilos de aprendizaje, motivaciones o intereses del alumnado, independientemente de su situación cultural, lingüística, social o de salud.

\section{Educación literaria en las primeras edades}

Durante el siglo XVIII se comienza a extender la idea de que los y las menores poseen características diferentes a las personas adultas y que, por ello, se debe atender a sus necesidades, creando una literatura específica acorde a ellos, la denominada literatura infantil y juvenil (LIJ), con unas particularidades específicas (Cerrillo, 2006). En la actualidad existe una amplia variedad de tipologías de materiales impresos para los más pequeños y pequeñas. Este trabajo se centra en el álbum ilustrado, ya que resulta especialmente apropiado para pre-lectores y pre-lectoras por el uso de la imagen como componente principal. El álbum se puede definir como "arte visual de imágenes secuenciales fijas e impresas afianzando en la estructura de libro, cuya unidad es la página, la ilustración es primordial y el texto puede ser subyacente" (Bosch, 2007, p. 41).

El acercamiento a la literatura en las primeras edades se lleva a cabo a partir del modelo pedagógico de la "educación literaria", basado en la formación del buen lector y el desarrollo de hábitos de lectura (Cerrillo, 2007). El objetivo primordial de este modelo es contribuir en la mejora de la competencia literaria, entendida como "un conjunto de saberes culturales, discursivos, textuales y pragmáticos" que permite al alumnado tanto "leer, comprender, interpretar y valorar distintos tipos de textos [literarios]" como "crear, recrear y producir sus propios textos literarios, tanto en forma oral como escrita" (Prado, 2004, p. 337). Un componente de esta competencia es el intertexto lector, entendido como "la percepción por el lector de relaciones entre una obra y otras que le han precedido o seguido" (Riffaterre, 1980, citado en Mendoza, 1999, p. 17).

Una de las actividades de este modelo pedagógico es la conversación literaria, la interacción y el intercambio verbal entre los menores y el adulto mediador, contribuyendo a la construcción compartida del conocimiento. Diversos autores (Chambers, 2007; Mercer y Littleton, 2007; Duran, 2007; Díaz-Plaja y Prats, 2016) señalan la importancia de la interacción y la conversación sobre los libros, pues el diálogo en torno a los mismos supone una fuente de aprendizaje sólida, abierta y múltiple. A su vez, contribuye a la mejora de la competencia literaria, en especial al progreso en las habilidades interpretativas. Existen diferentes modelos de conversación, entre los cuales el llamado "enfoque DIME" (Chambers, 2007) es el más conocido y empleado. Dicho enfoque busca la "conversación individual y al mismo tiempo comunitaria y cooperativa, pues cada participante debe escuchar lo que tienen que decir los otros y tomar en cuenta lo que piensan los demás del libro" (Chambers, 2007, p. 30). Este modelo de conversación literaria se apoya en varios tipos de preguntas basadas en las lecturas, comenzando por las básicas, después las generales y finalizando con las especiales.

Investigaciones como las llevadas a cabo por Sipe (2008), Sipe y Pantaleo (2008), Nikolajeva (2005), Lewis (2001), Pantaleo (2007; 2011), Amo y Ruiz (2011), y Ruiz-Dominguez (2014) han estudiado las respuestas lectoras de los menores y las menores lectores, creando sistemas de categorización y modelos para el análisis de los diferentes tipos de respuestas lectoras.

\section{Literatura e inclusión}

La LIJ permite explicar y entender una gran cantidad de conceptos, ya sean didácticos o sociales. Colomer (1998) señala que las conversaciones literarias pueden ser un gran recurso pedagógico para tratar textos con valores sociales, estéticos y literarios. De esta forma se le proporciona al lector una gran variedad de obras, ayudando a su desarrollo personal y a su formación como ciudadano y ciudadana.

La LIJ puede ayudar a desarrollar conductas sociales, afectivas o emocionales, ya que a través de la literatura se modifica la forma de ver la sociedad, las personas o las situaciones a las que se enfrentan (Cerrillo, 2016). A su vez, con la lectura de la literatura se expone al alumnado a situaciones de aprendizaje vivencial, experimentando a través de distintos hechos su moral (Chillón, 2004). El valor moral que transmite la literatura permite trabajar de manera sensible, directa y concisa una gran cantidad de conceptos y actitudes, comprendiendo, sencillamente, lo que transmiten (Sandoval y Carpena, 2013).

Asimismo, la LIJ contribuye al desarrollo de las capacidades cognitivas, sociales, artísticas, lingüísticas y emocionales de los 
menores. En este sentido, Colomer (2005) defiende la importancia de la literatura infantil destacando tres funciones: iniciar el acceso al imaginario colectivo, desarrollar el dominio de las formas narrativas, poéticas y dramáticas y ejercer una función socializadora de las nuevas generaciones a partir de la propuesta de una representación articulada del mundo.

Diversas investigaciones como la llevada a cabo por Petit (2001) exponen la idea de que la literatura es una forma de alcanzar la integración social, ya que a través de la misma se genera un entorno acogedor y de respeto, gracias a la actitud del narrador y los temas de conservación que se generan.

Por todo ello, a través de la lectura literaria se puede favorecer la inclusión desde diferentes perspectivas. Por un lado, la discusión sobre la temática, el contenido o los personajes de las obras literarias permiten tratar en el aula cuestiones como el respeto, la tolerancia, la inclusión o las diferencias. Autores como Ballester e Ibarra (2015) sostienen que la literatura ayuda a desarrollar las distintas competencias, entre las que destacan la competencia lingüística y la social y ciudadana, puesto que trata de fomentar en el alumnado recursos esenciales para comprender la realidad y actuar sobre la misma. Por otro lado, las prácticas de conversación literaria favorecen la inclusión, ya que ayudan a profundizar sobre el tema seleccionado, dialogando y compartiendo opiniones e ideas, así como respetando los turnos de palabra, las ideas de los demás y teniendo derecho a participar, a conversar y a ser escuchado por los demás. Por ello, la literatura fomenta un espacio de reflexión a través de la conversación que se genera en torno a la misma por parte de la voz de las personas participantes (Ballester et al., 2015). Además, el predominio de las imágenes en obras como los álbumes ilustrados puede favorecer la inclusión, ya que facilita el acceso a la obra al alumnado con dificultades de comprensión del lenguaje verbal, como un sistema aumentativo del lenguaje (Correa et al., 2011).

\section{Objetivos}

El propósito de la investigación es comprobar la adecuación de la lectura compartida de álbumes ilustrados, combinada con la práctica discusión literaria, para mejorar la inclusión del alumnado de un aula concreta de Educación Infantil. Asimismo, se pretende comprobar el impacto de estas prácticas pedagógicas en la mejora de la competencia literaria en este alumnado.

\section{Metodología}

Se trata de una investigación de tipo cualitativo de corte exploratorio. Concretamente, se trata de un estudio de caso, basado en el diseño, aplicación y posterior análisis de una sesión de lectura compartida de un álbum seguida de una conversación sobre el texto. Para valorar la contribución de la lectura compartida a la inclusión y al desarrollo de la competencia literaria, se lleva a cabo un análisis de las respuestas lectoras del alumnado durante y después de la lectura, tomando como referente los trabajos de Sipe (2008), Nikolajeva (2005), Lewis (2001), Pantaleo (2007; 2011) o Amo et al. (2011).

El álbum seleccionado para llevar a cabo la sesión ha sido Por cuatro esquinitas de nada (Ruillier, 2014). Este álbum ilustrado ha sido seleccionado de manera intencional, pues trata valores como la solidaridad, la resolución de problemas en grupo, la cooperación y la inclusión a través de un pequeño Cuadrado que quiere ir a jugar a casa de su grupo de amigos, los Redondos, pero no puede porque no entra por la puerta. Para la búsqueda del álbum se han consultado selecciones de lecturas recomendadas para el público infantil y páginas web especializadas en LIJ como el portal del grupo Gretel ${ }^{1}$, la Biblioteca Virtual Miguel de Cervantes²,

https://www.gretel.cat/?lang=es

http://www.cervantesvirtual.com/
Canal Lector $^{3}$ o Club Kirico ${ }^{4}$. Además, se ha prestado atención a la calidad de la obra -teniendo en cuenta los premios recibidos y el prestigio del autor y/o del ilustrador-, así como la adecuación a la edad. Se han tenido en cuenta criterios desarrollados por especialistas en LIJ como Colomer et al. (2018) o Lluch (2010) para la selección de lecturas y la propuesta de selección de lecturas por edades planteada por Cerrillo \& Yubero (1996). También se ha consultado con las maestras tutoras del alumnado participante para seleccionar una obra que no hubiera sido leída previamente en el aula.

La sesión se ha llevado a cabo en un centro público rural situado en una zona costera del occidente asturiano. La muestra (Tabla 1) se compone de un total de 34 sujetos ( 23 niños y 11 niñas) correspondientes a los tres grupos de educación infantil, de primer curso, del segundo curso y del tercer curso. La muestra ha sido seleccionada de manera intencional o no aleatoria, teniendo en cuenta la facilidad de acceso a los mismos y el interés de la dirección por conocer el nivel de inclusión en Educación Infantil.

Tabla 1. Participantes por grupo y sexo

\begin{tabular}{|l|c|c|c|}
\hline Grupo & Niños & Niñas & Total \\
\hline Primer curso (3-4 años) & 4 & 4 & 8 \\
\hline Segundo curso (4-5 años) & 9 & 5 & 14 \\
\hline Tercer curso (5-6 años) & 10 & 2 & 12 \\
\hline Total & 23 & 11 & 34 \\
\hline
\end{tabular}

Fuente: Elaboración propia

Existe bastante heterogeneidad entre los participantes, tanto por las diferencias de edad, como por los gustos, intereses, características personales, personalidad, carácter o capacidades individuales de cada niño o niña. La sesión de lectura se realizó con todos los participantes en su conjunto, ya que se ha comprobado que de esta forma el alumnado genera una respuesta comparti$\mathrm{da}$, construida y elaborada en base al texto y los conocimientos previos (Sipe, 2008). Para poder llevar a cabo la intervención se diseñó y envió un modelo de consentimiento informado para que las familias autorizasen la investigación y la grabación en audio de la lectura compartida

Para llevar a cabo la intervención, al inicio de la sesión, se presentó el álbum, planteando preguntas para generar hipótesis sobre la obra, continuando con la lectura compartida del álbum y finalizando con una conversación apoyada en las preguntas básicas, generales y específicas adaptadas al texto del enfoque DIME (Chambers, 2007).

\section{Análisis de datos}

El análisis de los datos se ha llevado a cabo a través de la metodología cualitativa-interpretativa (McMillan y Schumacher, 2001) ya que permite recabar las respuestas del alumnado y clasificarlas en temas y categorías. Para clasificar los temas y categorías han sido tenidas en cuenta investigaciones previas con una temática similar, como las llevadas a cabo por Silva-Díaz (2005), Sipe (2000, 2008) o Ruíz-Domínguez (2014). Para ello, se ha introducido la conversación en el software para el análisis cualitativo Atlas Ti, versión 6.2.29. Dicho software permite analizar e interpretar los comentarios obtenidos, teniendo en cuenta las categorías y temas previamente seleccionados.

Se han utilizado diferentes estrategias cualitativas de recogida de la información, como entrevistas con las maestras tutoras, la grabación de audio de la sesión de lectura, la observación parti-

\footnotetext{
https://canallector.com/

4 https://www.laslibreriasrecomiendan.com/kirico/
} 
cipante y el diario de campo. Las entrevistas con las tutoras han permitido conocer su percepción sobre la competencia literaria del alumnado y la inclusión. Las grabaciones de audio se han realizado para poder revisar posteriormente el desarrollo de las sesiones y transcribir los diálogos. Por último, la observación participante por parte de la investigadora se ha llevado a cabo durante el desarrollo de la sesión, focalizando su atención en todo el alumnado y atendiendo a la reacción de los iguales cuando un alumno o alumna intervenía. Todo ello ha permitido recopilar información y anotarla en un diario de campo tras finalizar la sesión.

Para analizar las respuestas lectoras del alumnado se estableció la siguiente categorización, teniendo en cuenta las aportaciones de Ruíz-Domínguez (2014).

\section{Categoría 1. Comprensión:}

Esta categoría engloba todas aquellas respuestas que muestran la comprensión de la historia por parte del alumnado. En palabras de Mendoza (1998) la comprensión se refiere a aquellas respuestas que muestran una construcción de significado realizada a partir de anticipaciones o expectativas.

\section{Categoría 2. Interpretación:}

Esta categoría incluye respuestas que revelan una reacción cognitiva o afectiva (Mendoza, 2008). Por ende, la interpretación implica ir más allá de lo que el texto narra y otorgarle un sentido personal. Por tanto, cada persona puede otorgar una interpretación diferente a una misma historia.

\section{Categoría 3. Relación:}

Esta categoría hace referencia a la vinculación que hace el alumnado entre el texto y las vivencias personales propias. En este caso, se tienen en cuenta las respuestas que relacionan la obra con situaciones de exclusión que han experimentado o situaciones que en las que han ayudado a otros niños y niñas a relacionarse. Por ende, se recogen todas las respuestas que realice el alumnado relacionadas con situaciones o anécdotas personales, ya sean positivas o negativas.

Además, se ha tenido en cuenta, de forma general, el grado de participación de los niños y niñas durante la sesión de lectura compartida.

\section{Resultados}

El análisis de la sesión ha permitido analizar las respuestas lectoras del alumnado durante la lectura y posterior conversación literaria sobre el álbum ilustrado Por cuatro esquinitas de nada. De modo general, se ha observado una alta y constante participación por parte de casi todo el grupo durante la sesión, exceptuando parte del alumnado con alguna necesidad específica de apoyo educativo. Dos alumnos con necesidades específicas de apoyo educativo, de los cinco que hay en todo infantil, han intervenido en menos ocasiones que los demás, haciendo uno o dos comentarios durante la sesión. Respecto a los niños y niñas con problemas de lenguaje, hablaron con un volumen de voz más bajo, pero aun así aportaron sus ideas y sus comentarios, aunque cometiesen errores de pronunciación.

\section{Categoría 1. Comprensión:}

En esta categoría se recogen las respuestas aportadas por el alumnado, anticipando sus respuestas a lo que va a suceder, narrando lo que hacen o piensan los personajes o intentando explicar las razones de conducta de los personajes.

Durante la lectura, el alumnado ha formulado observaciones que revelan su comprensión de la historia, apoyándose en las ilustraciones y en el texto. Por ejemplo, cuando en un momento de la historia apareció una sierra de cortar, un alumno gritó asustado “ipara que pueda entrar le van a cortar!". O cuando no podía entrar a jugar con sus compañeros comprendieron que la culpa no era suya, sino de la puerta que le impedía el paso, diciendo "hay que tirar la puerta abajo", "yo las haría de todas las formas del mundo, para que todos puedan entrar" o "poner una puerta cuadrada en otro sitio para que pueda entrar Cuadradito".

Al final de la sesión se le pidió a todo el alumnado resumir en una frase el mensaje de la historia. Algunas de las respuestas han sido: "todos queremos jugar juntos", "es mejor tener amigos que jugar solo" o "jugar juntos es más divertido".

Cabe destacar la gran capacidad de comprensión e imaginación de un niño de cuatro años, quien, sin haber leído el álbum anteriormente, aportó la solución que se da en la obra: "hacer un agujero que tenga forma de cuadrado".

\section{Categoría 2. Interpretación:}

Durante la lectura, hubo una gran variedad de comentarios personales de tipo interpretativo, todos ellos enfocados en una misma idea, conseguir que el cuadrado jugase con sus amigos. $\mathrm{Al}$ principio identificaron al personaje como "diferente a los demás" y poco a poco se dieron cuenta de las diferencias: algunos decían "porque no es redondo", "tiene esquinas y el agujero no tiene esquinas" o "no cabe".

Una diferencia que se ha encontrado es que los niños y niñas de tres años interpretaban de una forma más básica la historia, mientras que los de cuatro y cinco años ya hacían comentarios más complejos. Por ejemplo, en lo referido a cómo solucionar el problema de dejar entrar a cuadradito, los de tres años hicieron comentarios como "abrir nuevas puertas con la forma del círculo" mientras que los comentarios de los de cuatro o cinco años eran "modificar la puerta". En lo referido al mensaje de la historia, los de tres años decían "jugar juntos es mejor", mientras que los de cuatro años comentaban "jugando unidos aprendemos más" y los de cinco años "debemos dejar entrar para poder aprender".

Un diálogo que ejemplifica las respuestas o interpretativas surgidas a lo largo de la conversación literaria ha sido el siguiente:

- ¿Creéis que todos los niños y niñas pueden venir a nuestro cole?

-Sí.

- Imaginaos que viene un cuadradito niño, ¿puede entrar?

-Sí, pueden entrar todos, ya somos muy grandes para venir al cole.

- Pero, ¿creéis que pueden ir a todos los lugares del cole?

-Sí.

— ¿Incluso a la sala de ordenadores?

-Sí.

- ¿Qué hay que hacer para llegar a la sala de ordenadores? - Subir escaleras.

-Muy bien, ¿y todos los niños y niñas pueden subir escaleras?

- No podrían, porque hay escaleras y ellos no tienen patas.

- ¿Alguna persona en especial?

- Uno que no vea.

- Algunos que vayan en silla de ruedas.

- Esperad que aquí dijeron dos cosas importantes, dilo otra vez.

$-\mathrm{O}$ alguno que vaya en silla de ruedas.

- ¿Si vienen en silla de ruedas podrían subir a la sala? (La maestra de cuatro años coloca en el suelo unas figuras con niños en sillas de ruedas, con andadores, ciegas y en muletas). -No, necesitarían ayuda.

- ¿Y qué podemos hacer para ayudar a que vengan estas personas al cole?

-Darles la mano.

-O un ascensor, necesitamos un ascensor para el cole. 
-Y si viniese al cole una persona ciega, ¿podría ir a todos sitios?

-Tampoco.

- ¿Qué podríamos hacer?

- Guiarles.

-El ayudante del día puede estar con él para decirle por dónde tiene que caminar.

- ¿Y para que lea los carteles escritos?

- Escribir con puntos, como en los medicamentos.

\section{Categoría 3. Relación:}

Conversando sobre cuestiones más relacionadas con la temática del álbum se les preguntó si alguna vez se habían sentido como cuadradito, a lo que varios contestaron relacionando el álbum con experiencias personales. Una niña de tres años explicó que se sentía marginada cuando su hermano mayor no quería jugar con ella.

Otra niña de cinco años habló de sentirse excluida cuando su madre se iba de viaje sin ella. Un niño de cuatro años dijo que cuando había estado "malo de la pierna" se sentía mal por no poder jugar en el tobogán del colegio. Al hilo de esta afirmación se les preguntó sobre si creían que todos los niños o niñas podían venir a nuestro colegio.

Por otra parte, se apreció que nadie detectó nada en este álbum que le recordase a otros libros conocidos, a pesar de haber leído otros similares en el aula.

Un aspecto que no tiene cabida en ninguna de las categorías mencionadas con anterioridad ha sido la respuesta de una niña de cinco años, quien, al finalizar la sesión, decidió representar un "teatrillo" con las figuras de la niña en silla de ruedas, niño en muletas, niña ciega y un niño en un andador. Creó así una historia de más de diez minutos basada en estos personajes, donde se mostraba cómo se ayudaban los unos a los otros e iban a dar paseos y a jugar todos juntos.

\section{Discusión}

A la vista de los resultados, se puede considerar que el álbum seleccionado para llevar a cabo esta sesión inicial resultó apropiado: las respuestas formuladas por el alumnado durante la lectura compartida y la conversación posterior revelan que el alumnado ha entendido la idea de sentirse acogido y la importancia que tiene. Los niños y niñas participantes han demostrado una buena comprensión e interpretación de la historia, relacionando la obra con experiencias personales de exclusión.

El enfoque DIME (Chambers, 2008), adoptado para el desarrollo de la sesión, se reveló como un modelo pedagógico que favorece la conversación en torno al libro, pues permitió generar un conjunto de preguntas para ir guiando al alumnado a elaborar sus propias ideas, reflexiones y pensamientos y expresarlas junto a sus iguales. Además, se constató que es un modelo flexible, pues permite emplear las preguntas recomendadas junto con otras más específicas acordes al tema de la obra, lo que beneficia su empleo para diferentes obras literarias y nuevos temas. A su vez, el diálogo que se va creando facilita que todo el alumnado reflexione y profundice en la obra y en el mensaje de la misma, como se ha visto en este caso.

Se ha prestado especial atención al modo en que esta sesión ha contribuido a la mejora de la competencia literaria y la inclusión, por lo que a continuación se detallan ambos aspectos.

\section{Contribución al desarrollo de la competencia literaria}

El análisis de las respuestas demuestra una adecuada comprensión de la obra leída. Por ejemplo, todo el alumnado ha sido capaz de sintetizar en una breve frase el mensaje de la misma, aportando una interpretación personal sobre lo transcurrido. Las respuestas interpretativas que han realizado durante la sesión demuestran que han sido capaces de ofrecer una visión personal sobre la obra. La han relacionado con circunstancias de su vida personal, haciendo la obra "suya", aportando una lectura personal y única desde su perspectiva como receptor. Además, se ha visto cómo las ilustraciones han ayudado en la comprensión, pues han facilitado la realización de hipótesis sobre el qué pasará y servido como apoyo visual al texto narrado. También se aprecia que al emplear preguntas durante la lectura se fomenta la comprensión de la historia y la fijación en las ilustraciones, además de en los aspectos más importantes y relevantes. En cambio, la no identificación de conexiones con otras lecturas previas revela dificultades para activar el intertexto lector (Mendoza, 2008). Por ello, es un aspecto al que se le debe dar importancia y conviene insistir en futuras sesiones.

\section{Contribución a la mejora de la inclusión}

Por otra parte, el análisis de las respuestas revela que este enfoque podría servir para mejorar el clima y las relaciones entre el alumnado de Educación Infantil. En primer lugar, todo el alumnado ha participado, hablado y opinado en algún momento de la sesión. Además, se ha seguido un orden y se han respetado los turnos de palabra en cada momento. Por ende, todo el alumnado se ha sentido valorado y respetado por sus iguales, ya que han tenido la oportunidad de ofrecer su visión u opinión sobre la historia. En segundo lugar, dada la historia y la temática del álbum, la conversación ha permitido reflexionar sobre situaciones de exclusión que pueden darse en la vida cotidiana del aula o fuera de ella. Asimismo, algunos niños y niñas han encontrado un espacio en el que poder hablar y contar situaciones de exclusión o segregación que han experimentado. Ello permite que el profesado capte estas respuestas y actúe ante ellas, trabajándolo en el aula y atento a posibles situaciones de exclusión o segregación.

\section{Conclusiones}

La inclusión educativa aún supone un reto para muchos y muchas docentes (Marchesi, 2001) y crea confusión terminológica con la integración (Echeita 2008). Por ello, como docentes, es preciso conocer distintas herramientas que ayuden a desarrollar una educación inclusiva para todo nuestro alumnado, contribuyendo a su desarrollo integral.

La investigación desarrollada ha reflejado que la lectura compartida de álbumes y la conversación literaria puede mejorar la inclusión en el aula, pues facilita la relación entre iguales y da voz al alumnado, permitiéndole expresarse. Además, posibilita reflexionar sobre situaciones relacionadas con la inclusión a partir de las obras literarias que se llevan al aula, si la selección es adecuada. Otras investigaciones (Calvo et al., 2015; Calvo, 2019) reflejan resultados similares, afirmando que la lectura de álbumes contribuye a la mejora de la inclusión, ya que las ilustraciones permiten el seguimiento de la historia por todo el alumnado. Dichas autoras sostienen que el enfoque DIME facilita la creación de un espacio acogedor en el que poder hablar, escuchar y compartir un rato de lectura, además de servir para recordar la historia. Otras investigaciones (Tabernero, 2015) sostienen que el álbum ilustrado es un soporte idóneo para relacionar el individualismo con la idea de comunidad y sociedad. De igual modo, Ballester et al. (2015) sostienen que la conversación literaria favorece la inclusión por su capacidad de generar un entorno conjunto de reflexión.

Por otro lado, también se ha reflejado cómo el enfoque DIME contribuye a la mejora de la competencia literaria, pues permite profundizar en la interpretación compartida. Además, también favorece el desarrollo de habilidades comunicativas, ya que, a través del diálogo, el alumnado se expresa, ampliando su vocabulario. De acuerdo con Calvo et al. (2015), se puede afirmar que el lenguaje repetitivo, los diálogos o la estructura sencilla, acompañados de las ilustraciones, ayudan a los lectores y lectoras a 
comprender e interpretar el texto, así como a entender las reglas narrativas. Por otro lado, Petit (2015) confirma la lectura como un procedimiento que permite la reflexión y expresión de emociones, así como forjar vínculos con la realidad. Además, se contribuye al desarrollo del gusto por la lectura, pues, con estas sesiones se fomenta el hábito lector, leyendo en clase una o varias veces por semana.

No obstante, cabe señalar que se ha empleado una muestra reducida y no aleatoria, por lo que en el futuro se pretende ampliar la investigación con un mayor número de participantes. También se quiere aumentar el número de sesiones de lectura, lo que conlleva un mayor número de álbumes. De esta forma, se podrá confirmar si, efectivamente, la lectura de álbumes ilustrados, unida a la conversación literaria, favorece la adquisición de la competencia literaria y la inclusión ocurre, tal como sugieren los resultados obtenidos en este estudio de caso. En el futuro desarrollo de esta investigación, también se considera conveniente hacer hincapié en las preguntas dirigidas al desarrollo del intertexto lector.

\section{Agradecimientos}

Este trabajo no ha recibido financiación alguna por parte de ninguna entidad, gobierno o agencia colaboradora.

\section{Referencias}

Ainscow, M. \& Booth, T. (2011). Index for Inclusion: Developing learming and participation in schools. CSIE.

Alba, C., Sánchez, J. M. \& Zubillaga, A. (2014). Diseño Universal para el Aprendizaje. Pautas para su introducción en el currículo [en línea]. Edelvives. https://www.educadua.es/doc/dua/dua_ pautas_intro_cv.pdf

Amo, J. M. de \& Ruiz, M. (2011). Identificación de las facetas metaliterarias en la recepción del álbum ilustrado. En A. M. Ramos e I. Mociño (Eds.), Crítica e Investigación en Literatura Infantil y Juvenil (pp. 237-257). ANILIJ/ Universidade do Minho.

Arnaiz, P. (2000). La diversidad como valor educativo. En I. Martín (Coord.), El valor educativo de la diversidad (pp. 87-103). Grupo Editorial Universitario.

Ballester, J. \& Ibarra, N. (2015). La formación lectora y literaria en contextos multiculturales: Una perspectiva educativa e inclusiva. Teoría de la Educación: Revista Interuniversitaria, 22, 161-183. http://dx.doi.org/10.14201/teoredu2015272161183

Blanco, R. (Coord.). (2010). El derecho de todos a una educación de calidad. Revista Latinoamericana de Educación Inclusiva, 4(2), 25-153.

Bosch, E. (2007). Hacia una definición de álbum. Anuario de investigación en literatura infantil y juvenil, 5, 25-46. https://somiari. files.wordpress.com/2011/07/2007_bosch_haciadefinicionalbum_pet.pdf

Calvo, V. (2019). El diario de lectura en los procesos de acogida de familias inmigrantes. Ocnos, 18(1), 41-51. https://doi. org/10.18239/ocnos_2019.18.1.1789

Calvo, V. \& Tabernero, R. (2015). El álbum ilustrado en contextos inclusivos: Estudio de casos en niños con trastorno del espectro autista. Revista nacional e internacional de educación inclusi$v a, 8(3), 47-66$.

Cerrillo, P. (Dir.). (2006). La motivación a la lectura a través de la literatura infantil. Ministerio de Educación y Ciencia, Subdirección General de Información y Publicaciones.

Cerrillo, P. C. (2007). Literatura infantil y juvenil y educación literaria. Octaedro.

Cerrillo, P. C. (2016). La importancia de la literatura infantil y juvenil en la educación literaria. En A. Díez, V. Brotons, D. Escandell y J. Rovira (Eds.), Aprendizajes plurilingües y literarios: Nuevos enfoques didácticos (pp. 32-41). http://rua.ua.es/dspace/ handle/10045/64749
Cerrillo, P. C. \& Yubero, S. (1996). Qué leer y en qué momento. En P.C. Cerrillo y J. Padrino (Coords.), Hábitos lectores y animación a la lectura (pp. 47-58). Ediciones de la Universidad de Castilla-La Mancha.

Chambers, A. (2007). Dime: los niños, la lectura y la conversación. Fondo de Cultura Económica.

Chaves, A., Do Nascimento, L. \& Castellar, S. (2018). Imágenes de la educación inclusiva: algunos apuntes acerca del espacio y del tiempo escolares. Anenkumeme, 1 (3), 42-51. https://revistas. pedagogica.edu.co/index.php/anekumene/article/view/7349

Chillón, G. D. (2004). Los valores en la educación infantil. La Muralla.

Colomer, T. (1998). La formación del lector literario. Fundación Germán Sánchez Ruipérez.

Colomer, T. (2005). Las funciones de la literatura infantil y el contexto actual. En M. Abril (Coord.), Lectura y literatura infantil y juvenil: claves (pp. 25-48). Aljibe.

Colomer, T., Manresa, M., Ramada Prieto, L \& Reyes López, L. (2018). Narrativas literarias en educación infantil y primaria. Síntesis.

Correa, A.D., Correa, T. \& Pérez, D. (2011). Comunicación aumentativa: Una introducción conceptual y práctica. Universidad de la Laguna.

Decreto 85/2008, de 3 de septiembre, por el que se establece el currículo del segundo ciclo de Educación Infantil. Boletín Oficial del Principado de Asturias, 212, (11/09/2008).

Díaz-Plaja, A. \& Prats, M. (2016). Conversar sobre libros. En M. Fons Esteve y J. PalouSangrà (Coords.), Didáctica de la lengua y la literatura en Educación Infantil (pp. 65-74). Síntesis.

Duran, D. (2007). Llegim en parella, un programa de tutoria entre iguals, ambalumnes i famílies, per a la millora de la competència lectora. Articles de didàctica de la llengua $i$ de la literatura, 42, 85-99.

Echeita, G. (2006). Educación para la inclusión. Educación sin exclusiones. Narcea.

Echeita, G. (2008). Inclusión y exclusión: Voz y quebranto. REICE: Revista Electrónica Iberoamericana sobre Calidad, Eficacia y Cambio en Educación, 6(2), 9-18.

González-Gil, F, Martín-Pastor, E. \& Orgaz Baz, B. (2017). ¿Están los futuros profesores formados en inclusión?: Validación de un cuestionario de evaluación. Aula Abierta, 46(2), 33-40.

Jiménez, M., Rodríguez, H., Sánchez, S., \& Rodríguez, J. (2018). Construcción del discurso en torno a la Educación Inclusiva. Revista Electrónica Interuniversitaria de Formación del Profesorado, 21 (1), 185-217. https://doi.org/10.6018/reifop.21.1.305771

Ley Orgánica 2/2006, de 3 de mayo, de educación. Boletín Oficial del Estado, 106, (04/05/2006).

Ley Orgánica 8/2013, de 9 de diciembre, para la mejora de la calidad educativa. Boletín Oficial del Estado, 295, (10/12/2013).

Lewis, D. (2001). Reading Contemporary Picturebooks: Picturing Text. Routledge/Falmer.

Lluch, G. (2010). Cómo seleccionar libros para niños y jóvenes. Los comités de valoración en las bibliotecas escolares y públicas. Trea.

Marchesi, A. (2001). La práctica de las escuelas inclusivas. En A. Marchesi, C. Coll y J. Palacios (Comp.), Desarrollo psicológico y educación: Trastornos del desarrollo y necesidades educativas especiales (pp. 45-74). Alianza.

McMillan, J. \& Schumacher, S. (2001). Research in Education. A conceptual introduction. Longman.

Mendoza, A. (1998). Tu lector. Aspectos de la interacción texto-lector en el proceso de lectura. Octaedro.

Mendoza (1999). Función de la literatura infantil y juvenil en la formación de la competencia literaria. En Cerrillo, P. C. y García Padrino, J. (Coords.), Literatura infantil y su didáctica (pp.11-53). Universidad de Castilla-La Mancha.

Mendoza, A. (2008). El canon formativo y la educación lecto-literaria. En A. Mendoza (Coord.), Didáctica de la lengua y la literatura (pp. 349-378). Pearson Education. 
Mercer, N. \& Littleton, K. (2007). Dialogue and the Development of Children's Thinking: A sociocultural Approach. Routledge.

Nikolajeva, M. (2005). Aesthetic Approaches to Children's Literature. An Introduction. The Scarecrow Press Inc.

Organización de las Naciones Unidas para la Educación, Ciencia y la Cultura (UNESCO). (2004). Una Educación de Calidad para Todos los Jóvenes: Desafíos, Tendencias y Prioridades. En Oficina Internacional de Educación de la UNESCO. Conferencia Internacional de Educación, 47 reunión. https://unesdoc.unesco.org/ ark:/48223/pf0000140735_spa

Pantaleo, S. (2007). Scieszka's The Stinky Cheese Man: A Tossed Salad of Parodic Reversions. Children's Literature in Education, 38, 277-295.

Pantaleo, S. (2010). Mutinous Fiction: Narrative and Illustrative Metalepsis in Three Postmodern Picturebooks. Children's Literature in Education, 41, 12-27.

Petit, M. (2001). Lecturas: del espacio íntimo al espacio público. FCE.

Prado, J. (2004). Didáctica de la lengua y la literatura para educar en el siglo XXI. La Muralla.

Ruillier, J. (2014). Por cuatro esquinitas de nada. Juventud.
Ruíz-Domínguez, M. (2014). Estrategias metaficcionales y respuestas lectoras: estudio exploratorio. Ocnos, 11, 45-69. https://doi.org/10.18239/ocnos_2014.11.03

Sandoval, C \& Carpena, Á. (2013). Educando para la diversidad a través del cuento. Aula de Innovación Educativa, 221, 48-52.

Silva-Díaz, M. C. (2005). Libros que enseñan a leer: álbumes metaficcionales y conocimiento literario. http://www.tesisenxarxa. net/TDX-0621106-000248/

Sipe, L. R. (2000). The Construction of Literary Understanding by First and Second Graders in Oral Response to Picture Storybook Read-Alouds. Reading Research Quarterly, 35 (2), 252-275.

Sipe, L. R. (2008). Storytime. Young Children's Literary Understanding in the Classroom. Columbia University.

Sipe, L. R., \& Pantaleo, S. (2008). Postmodern picturebooks: play, par$o d y$, and self-referentiality. Routledge.

Tabernero, R. (2015). ¿De qué sirve un libro sin dibujos ni diálogos? Álbum y formación de lectores literarios. En C. Romea; M. Soledad Muñoz; A. Herrero (Eds), Propuestas y experiencias sobre estructuras hipertextuales literarias en el aula (pp. 2834). Octaedro. 